\title{
Inequalities in access to water and soap matter for the COVID-19 response in sub-Saharan Africa
}

\author{
Safia S. Jiwani ${ }^{1 *+}$ (D) and Daniel A. Antiporta ${ }^{2 \dagger}$
}

\begin{abstract}
The COVID-19 pandemic has spread rapidly since the first case notification of the WHO in December 2019. Lacking an effective treatment, countries have implemented non-pharmaceutical interventions including social distancing measures and have encouraged maintaining adequate and frequent hand hygiene to slow down the disease transmission. Although access to clean water and soap is universal in high-income settings, it remains a basic need many do not have in low- and middle-income settings.

We analyzed data from Demographic and Health Surveys (DHS) of 16 countries in sub-Saharan Africa, using the most recent survey since 2015. Differences in the percentage of households with an observed handwashing place with water and soap were estimated by place of residence and wealth quintiles. Equiplots showed wide withincountry disparities, disproportionately affecting the poorest households and rural residents, who represent the majority of the population in most of the countries.

Social inequalities in access to water and soap matter for the COVID-19 response in sub-Saharan Africa. Interventions such as mass distribution of soap and ensuring access to clean water, along with other preventive strategies should be scaled up to reach the most vulnerable populations.
\end{abstract}

Keywords: Inequalities, Hand hygiene, Water and soap, COVID-19, Sub-Saharan Africa

The COVID-19 pandemic has spread across 185 countries [1] with overwhelming rates of viral transmission. The sub-Saharan African region is believed yet to reach its peak of the epidemic curve, with over 46,000 cases reported as of May 12th [2]. Lacking a safe and effective vaccine, countries have implemented strategies to slow the transmission of disease and prevent the overburdening of their health systems. However, social inequalities in this region challenge an equitable response to the pandemic.

\footnotetext{
* Correspondence: sjiwani1@jhu.edu

†Safia S. Jiwani and Daniel A. Antiporta contributed equally to this work. ${ }^{1}$ Department of International Health, Johns Hopkins Bloomberg School of Public Health, 615 N Wolfe St, Baltimore, MD 21205, USA

Full list of author information is available at the end of the article
}

Social distancing measures such as home-stay policies and curfews have been put in place globally. These measures, though necessary, are difficult to implement in a region like sub-Saharan Africa, where more than $40 \%$ of people live under 1.9 USD a day [3], and up to two thirds of jobs come from the informal sector [4], precluding many from health insurance and secured income. Overcrowding and informal settlements further exacerbate the feasibility of such mitigation strategies, particularly in a region where the median average household size is 4.8, surpassing 8 in countries such as Senegal and The Gambia [5].

Besides home-stay policies, handwashing with water and soap $[6,7]$ is one of the most effective interventions, recommended by the $\mathrm{WHO}$ and the $\mathrm{CDC}$, to minimize the risk of infection at community-level. While access to 
water and sanitation is universal in high-income settings, it remains a basic need that many do not have in sub-Saharan Africa.

We analyzed the most recent Demographic and Health Surveys (DHS) of 16 countries in sub-Saharan Africa since 2015. The DHS are nationally-representative household surveys that provide data on health and population indicators [8]. Our main outcome was the proportion of households having water and soap where a place for handwashing was observed. Inequalities were estimated using absolute differences between urban and rural, as well as richest and poorest households, and visualized using equiplots weighted by the population size.

The results from 16 countries in sub-Saharan Africa indicate that, on average, only $33.5 \%$ of households with an observed handwashing place at home have water and soap. We found large differences across countries, with national estimates ranging from $5 \%$ in Burundi to $64 \%$ in Angola, albeit covering different time periods between 2015 and 2018. Rural residents, who represent the majority of the population in the region, have a much lower access compared to their urban counterparts. Urbanrural disparities are wide in all countries, reaching up to 41.8 percentage points in Rwanda, where rural residents represent $82.8 \%$ of the total population and only a quarter of them have access to handwashing with water and soap. This basic need remains astonishingly low even in urban areas in countries such as Malawi (16.9\%), where the urban-rural gap is narrower. In contrast, Angola presents a different pattern where more than $50 \%$ of both urban and rural residents have access to adequate hand hygiene.

Inequalities between the richest and poorest households are as alarming, revealing gaps as large as 63.7 percentage points in South Africa. Burundi had the lowest access regionally, showing $3.8 \%$ of rural residents and $1.7 \%$ of the poorest households having water and soap at home. Equiplots by place of residence and wealth are shown in Fig. 1. Our findings are based on the households in which a fixed or mobile place used for handwashing was observed, which ranges from $99 \%$ in Burundi to $11 \%$ in Rwanda. Thus, households that did not have a handwashing place in the dwelling or did not allow the interviewer to observe the facility are not included in our analyses.

As the region faces a ravaging and highly contagious virus, many still do not have the basic human right of clean water nor soap for handwashing in their homes. It has never been more urgent to ensure access to essential hand hygiene needs, especially for the rural and poorest who are in a battlefield without this simple, yet powerful, shield against COVID-19. The relevance of access to adequate hand hygiene to prevent the spread of disease ought to be considered by public health officials and scientists for program implementation and disease transmission modelling purposes, respectively.

Action has been taken on this front in several countries in the region where handwashing stations with soap were implemented at public transportation sites in the past months as an early response to the pandemic [9,
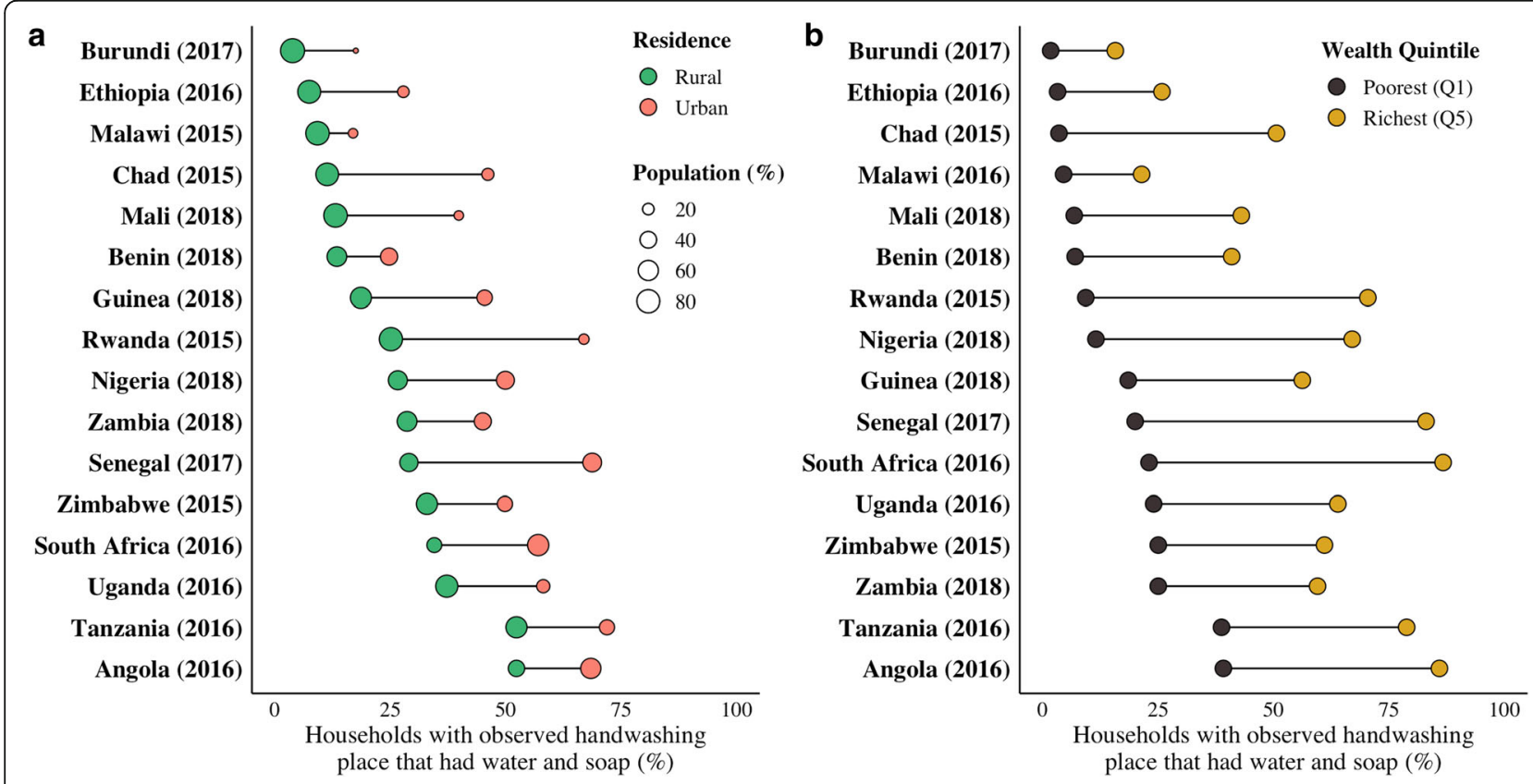

Fig. 1 Inequalities in the proportion of households with an observed handwashing place that had water and soap, by place of residence (panel a) and wealth (panel b) 
10]. Similarly, "tippy taps" have been put in place and are designed to enable safe handwashing specifically in rural areas with no running water [11]. We applaud these strategies and suggest that interventions such as mass distribution of soap and ensuring access to clean water, along with other preventive strategies be widely scaled up, particularly in rural areas and informal settlements.

\section{Acknowledgements}

The authors acknowledge governments and organizations in sub-Saharan Africa in their efforts towards containing the spread and reducing the impact of COVID-19 among vulnerable populations.

\section{Authors' contributions}

SSJ conceived the idea. SSJ and DAA equally contributed to the analysis and writing of this comment. DAA developed the data visualization. The authors read and approved the final manuscript.

\section{Funding}

None.

\section{Availability of data and materials}

The datasets generated and/or analyzed during the current study are available at https://dhsprogram.com/data/available-datasets.cfm or https:// www.statcompiler.com/en/

\section{Ethics approval and consent to participate}

Ethics approval and consent to participate were not needed for this secondary analysis of publicly available data.

\section{Consent for publication}

Not applicable.

\section{Competing interests}

The authors declare that they have no competing interests.

\section{Author details}

${ }^{1}$ Department of International Health, Johns Hopkins Bloomberg School of Public Health, 615 N Wolfe St, Baltimore, MD 21205, USA. ${ }^{2}$ Department of Epidemiology, Johns Hopkins Bloomberg School of Public Health, Baltimore, MD, USA.

Received: 23 April 2020 Accepted: 20 May 2020

Published online: 03 June 2020

\section{References}

1. Johns Hopkins University. COVID-19 dashboard by the Center for Systems Science and Engineering (CSSE) at Johns Hopkins University. https:// coronavirus.jhu.edu/map.html (Accessed 12 Apr 2020).

2. World Health Organization. Coronavirus disease (COVID-2019) situation report-113. Geneva: WHO; 2020. https://www.who.int/docs/default-source/ coronaviruse/situation-reports/20200512-covid-19-sitrep-113.pdf?sfvrsn= feac3b6d_2 (Accessed 12 May 2020).

3. Atamanov A, Castaneda Aguilar RA, Diaz-Bonilla C, et al. Global poverty monitoring technical note 10: September 2019 PovcalNet update what's new. Washington, D. C. World Bank Group; 2019. http://documents. worldbank.org/curated/en/344401569259571927/pdf/September-2019PovcalNet-Update-Whats-New.pdf (Accessed 12 Apr 2020).

4. Media $L$, Jonelis AW, Cangul M. The informal economy in sub-Saharan Africa: size and determinants. Washington, D. C.: International Monetary Fund; 2017. https://www.imf.org/en/Publications/WP/Issues/2017/07/10/TheInformal-Economy-in-Sub-Saharan-Africa-Size-and-Determinants-45017 (Accessed 12 Apr 2020).

5. UN Department of Social Affairs and Economics, Population Division. Patterns and trends in household size and composition: evidence from a United Nations dataset. 2019. https://www.un.org/en/development/desa/ population/publications/pdf/ageing/household_size_and_composition_ technical_report.pdf (Accessed 12 April 2020).
6. World Health Organization. Clean care is safer care. https://www.who.int/ gpsc/clean hands protection/en/ (Accessed 12 April 2020).

7. Centers for Disease Control and Prevention. Coronavirus disease 2019 (COVID-19): how to protest yourself \& others. https://www.cdc.gov/ coronavirus/2019-ncov/prevent-getting-sick/prevention.html (Accessed 12 April 2020).

8. The demographic and health survey program. https://dhsprogram.com/ (Accessed 12 Apr 2020).

9. Dalglish SL. Correspondence COVID-19 gives the lie to global health a role for CT in really tell us so far. Lancet. 2020;395:1189.

10. Anita Powell. 'Wash your hands' is tough message across Africa. 2020. https://www.voanews.com/science-health/coronavirus-outbreak/wash-yourhands-tough-message-across-africa (Accessed 12 May 2020).

11. World Health Organization Regional Office for Africa. Hand washing with the tippy tap. https://www.afro.who.int/node/12469 (Accessed 12 May 2020).

\section{Publisher's Note}

Springer Nature remains neutral with regard to jurisdictional claims in published maps and institutional affiliations.

\section{Ready to submit your research? Choose BMC and benefit from:}

- fast, convenient online submission

- thorough peer review by experienced researchers in your field

- rapid publication on acceptance

- support for research data, including large and complex data types

- gold Open Access which fosters wider collaboration and increased citations

- maximum visibility for your research: over $100 \mathrm{M}$ website views per year

At $\mathrm{BMC}$, research is always in progress.

Learn more biomedcentral.com/submissions 